\title{
THE EVOLUTION OF SPEED IN ATHLETICS: WHY THE FASTEST RUNNERS ARE BLACK AND SWIMMERS WHITE
}

\author{
ADRIAN BEJAN ${ }^{1}$, EDWARD C. JONES ${ }^{2} \&$ JORDAN D. CHARLES ${ }^{1}$ \\ ${ }^{1}$ Duke University, Department of Mechanical Engineering and Materials Science, Durham, NC, USA. \\ ${ }^{2}$ Howard University, Department of Nutritional Sciences, Washington, DC, USA.
}

\section{ABSTRACT}

Here we explain a much avoided phenomenon in the evolution of speed sports for men and women: The world records in running tend to be set by black athletes and in swimming by white athletes. We show that this phenomenon is predictable from physics. Locomotion is a 'falling-forward' cycle, in which body mass falls forward and then rises again. Mass that falls from a higher altitude falls faster, down and forward. In running, the altitude $\left(\mathrm{L}_{1}\right)$ is set by the position of the center of mass above the ground. In swimming, the altitude is set by the upper body rising above the water, and it is proportional to $\mathrm{H}-\mathrm{L}_{1}$, where $\mathrm{H}$ is the height of the athlete. The anthropometric literature shows that the center of mass in blacks is 3 percent higher above the ground than in whites. This means that blacks hold a 1.5 percent speed advantage in running, and whites hold a 1.5 percent speed advantage in swimming. Among athletes of the same height Asians are even more favored than whites in swimming but they are not setting records because they are not as tall.

Keywords: animal locomotion, constructal, evolution, running, speed sports, swimming.

\section{THE PHENOMENON: BLACK VERSUS WHITE IN SPEED SPORTS}

Speed records increase in time. Figure 1 shows two examples that cover the past century: men's record speeds in running ( $100 \mathrm{~m}$ dash) and swimming (100 $\mathrm{m}$ freestyle). They illustrate the evolution of the speed sports, not the evolution of an individual athlete in training. The evolution of the sport is the morphing of the societal 'flow system' in which faster individuals from the large population are recruited and trained in constantly improving institutions and facilities. The few athletes who are remembered for having climbed once on the highest podium are a small sample of how the performance of the population of runners and swimmers is evolving in time.

In a recent paper [1] we showed that the steady increases in winning speed are accompanied by increases in body mass and height. We showed that this speed-mass (or speed-height) relation is predictable from the constructal-theory scaling of animal speed versus body size [2].

Examined more closely, the evolution of the speed sports (Fig. 1) reveals a phenomenon that is as obvious as it is obviously not discussed. More and more, the winning runners are black athletes, particularly of West African orgin, and the winning swimmers are white. More and more, the world finalists in sprint are black and in swimming are white (Fig. 1). Here, we show that this evolutionary phenomenon too is predictable, and is an integral part of the phenomenon of speed evolution in modern athletics.

Our approach is to study phenotypic (somatotypic) differences of human locomotion in different media (terrestrial vs. aquatic), which we consider to have been historically misclassified as racial characteristics. These differences represent consequences of still not well-understood variable environmental stimuli for survival fitness in different parts of the globe during thousands of years of habitation [3-6]. Our study does not advance the notion of race, now recognized as a social construct, as opposed to a biological construct. We acknowledge the wide phenotypic and genotypic diversity among the so-called racial types. 


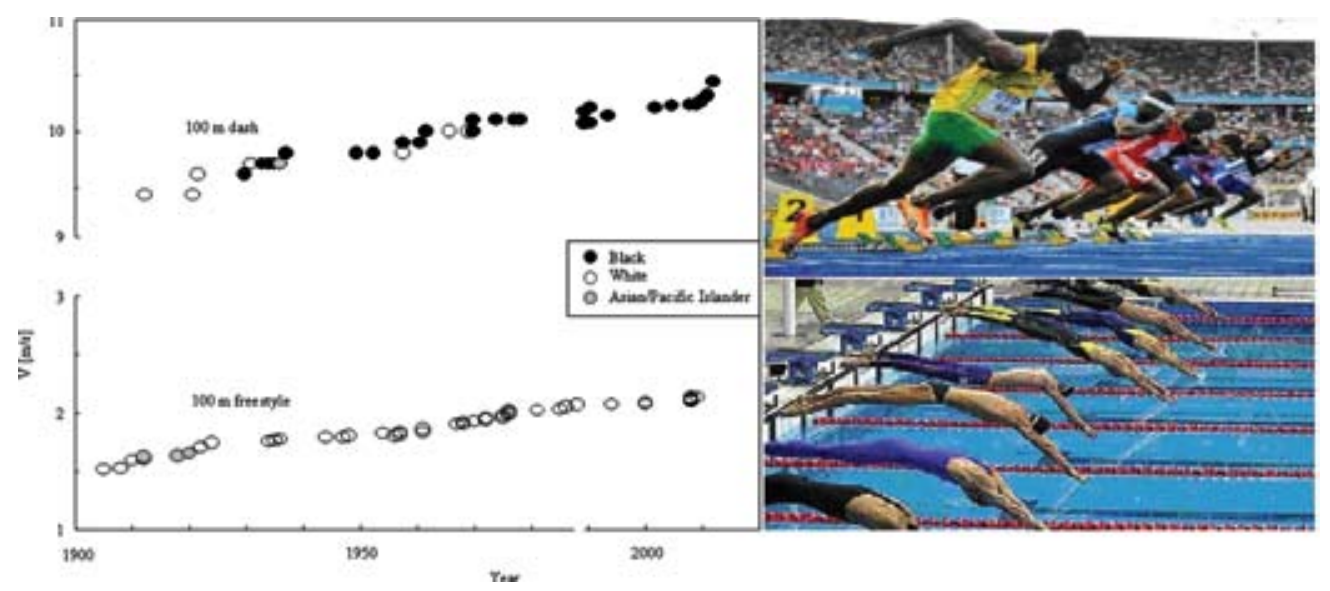

Figure 1: The evolution of men's world record speeds in running (100 $\mathrm{m}$ dash) and swimming (100 m freestyle) in modern athletics. The data are from Tables 1 and 2.

Table 1: Men's $100 \mathrm{~m}$ freestyle world records.

\begin{tabular}{llccl}
\hline Year & \multicolumn{1}{c}{ Name } & Time $(\mathrm{s})$ & Velocity $(\mathrm{m} / \mathrm{s})$ & \multicolumn{1}{c}{ Race } \\
\hline 1905 & Zoltan Halmay & 65.8 & 1.52 & White \\
1908 & Charles Daniels & 65.6 & 1.52 & White \\
1910 & Charles Daniels & 62.8 & 1.59 & White \\
1912 & Kurt Bretting & 62.4 & 1.60 & White \\
1912 & Duke Kahanamoku & 61.6 & 1.62 & Asian/Pacific Islander \\
1918 & Duke Kahanamoku & 61.4 & 1.63 & Asian/Pacific Islander \\
1920 & Duke Kahanamoku & 60.4 & 1.66 & Asian/Pacific Islander \\
1922 & Johnny Weissmuller & 58.6 & 1.71 & White \\
1924 & Johnny Weissmuller & 57.4 & 1.74 & White \\
1934 & Peter Fick & 56.8 & 1.76 & White \\
1935 & Peter Fick & 56.6 & 1.77 & White \\
1936 & Peter Fick & 56.4 & 1.77 & White \\
1944 & Alan Ford & 55.9 & 1.79 & White \\
1947 & Alex Jany & 55.8 & 1.79 & White \\
1948 & Alan Ford & 55.4 & 1.81 & White \\
1954 & Dick Cleveland & 54.8 & 1.82 & White \\
1956 & John Henricks & 55.4 & 1.81 & White \\
1957 & John Devitt & 55.2 & 1.81 & White \\
1957 & John Devitt & 54.6 & 1.83 & White \\
1961 & Steve Clarke & 54.4 & 1.84 & White \\
1961 & Manuel Dos Santos & 53.6 & 1.87 & White \\
1967 & Ken Walsh & 52.6 & 1.90 & White \\
1968 & Zachary Zorn & 52.5 & 1.90 & White \\
1968 & Michael Wenden & 52.2 & 1.92 & White \\
1970 & Mark Spitz & 51.9 & 1.93 & White \\
\hline
\end{tabular}


Table 1: Continued

\begin{tabular}{llccc}
\hline Year & \multicolumn{1}{c}{ Name } & Time $(\mathrm{s})$ & Velocity $(\mathrm{m} / \mathrm{s})$ & Race \\
\hline 1972 & Mark Spitz & 51.47 & 1.94 & White \\
1972 & Mark Spitz & 51.22 & 1.95 & White \\
1975 & James Montgomery & 51.12 & 1.96 & White \\
1975 & Andrew Cohen & 51.11 & 1.96 & White \\
1975 & James Montgomery & 50.59 & 1.98 & White \\
1976 & James Montgomery & 50.39 & 1.98 & White \\
1976 & James Montgomery & 49.99 & 2.00 & White \\
1976 & Jonty Skinner & 49.44 & 2.02 & White \\
1981 & Rowdy Gains & 49.36 & 2.03 & White \\
1985 & Matt Biondi & 49.24 & 2.03 & White \\
1986 & Matt Biondi & 48.74 & 2.05 & White \\
1988 & Matt Biondi & 48.42 & 2.07 & White \\
1994 & Alexander Popov & 48.21 & 2.07 & White \\
2000 & Michael Klim & 48.18 & 2.08 & White \\
2000 & Pieter van den Hoogenband & 47.84 & 2.09 & White \\
2008 & Alain Bernard & 47.60 & 2.10 & White \\
2008 & Alain Bernard & 47.50 & 2.11 & White \\
2008 & Eamon Sullivan & 47.24 & 2.12 & White \\
2008 & Alain Bernard & 47.20 & 2.12 & White \\
2008 & Eamon Sullivan & 47.05 & 2.13 & White \\
2009 & Cesar Cielo & 46.91 & 2.13 & White \\
\hline
\end{tabular}

Table 2: Men's $100 \mathrm{~m}$ dash world records.

\begin{tabular}{llccl}
\hline Year & \multicolumn{1}{c}{ Name } & Time $(\mathrm{s})$ & Velocity $(\mathrm{m} / \mathrm{s})$ & Race \\
\hline 1912 & Don Lippincott & 10.6 & 9.43 & White \\
1920 & Jackson Sholz & 10.6 & 9.43 & White \\
1921 & Charlie Paddock & 10.4 & 9.62 & White \\
1929 & Eddie Tolan & 10.4 & 9.62 & Black \\
1930 & Percy Williams & 10.3 & 9.71 & White \\
1932 & Eddie Tolan & 10.3 & 9.71 & Black \\
1932 & Ralph Metcalfe & 10.3 & 9.71 & Black \\
1933 & Ralph Metcalfe & 10.3 & 9.71 & Black \\
1934 & Eulace Peacock & 10.3 & 9.71 & Black \\
1934 & Chris Berger & 10.3 & 9.71 & White \\
1934 & Ralph Metcalfe & 10.3 & 9.71 & Black \\
1935 & Takanori Yoshioka & 10.3 & 9.71 & Asian/Pacific Islander \\
1936 & Jesse Owens & 10.2 & 9.80 & Black \\
1948 & Lloyd LaBeach & 10.2 & 9.80 & Black \\
1948 & Barney Ewell & 10.2 & 9.80 & Black \\
1951 & Emmanuel McDonald Bailey & 10.2 & 9.80 & Black \\
1956 & Bobby Joe Morrow & 10.2 & 9.80 & White \\
\hline
\end{tabular}


Table 2: Continued

\begin{tabular}{llccc}
\hline Year & \multicolumn{1}{c}{ Name } & Time $(\mathrm{s})$ & Velocity $(\mathrm{m} / \mathrm{s})$ & Race \\
\hline 1956 & Willie Williams & 10.1 & 9.90 & Black \\
1959 & Ray Norton & 10.1 & 9.90 & Black \\
1960 & Armin Hary & 10.0 & 10.00 & White \\
1960 & Harry Jerome & 10.0 & 10.00 & Black \\
1964 & Horacio Estaves & 10.0 & 10.00 & White \\
1964 & Bob Hayes & 10.0 & 10.00 & Black \\
1967 & Jim Hines & 10.0 & 10.00 & Black \\
1967 & Enrique Figuerola & 10.0 & 10.00 & White \\
1968 & Paul Nash & 10.0 & 10.00 & Black \\
1968 & Charles Greene & 10.0 & 10.00 & Black \\
1968 & Jim Hines & 9.9 & 10.10 & Black \\
1968 & Ronnie Ray Smith & 9.9 & 10.10 & Black \\
1968 & Charles Greene & 9.9 & 10.10 & Black \\
1972 & Eddie Hart & 9.9 & 10.10 & Black \\
1972 & Reynaud Robinson & 9.9 & 10.10 & Black \\
1972 & Steve Williams & 9.9 & 10.10 & Black \\
1975 & Silvio Leonard & 9.9 & 10.10 & Black \\
1976 & Harvey Glance & 9.9 & 10.10 & Black \\
1976 & Don Quarrie & 9.9 & 10.10 & Black \\
1987 & Carl Lewis & 9.93 & 10.07 & Black \\
1987 & Ben Johnson & 9.83 & 10.17 & Black \\
1988 & Ben Johnson & 9.79 & 10.21 & Black \\
1988 & Carl Lewis & 9.92 & 10.08 & Black \\
1991 & Carl Lewis & 9.86 & 10.14 & Black \\
1999 & Maurice Greene & 9.79 & 10.21 & Black \\
2002 & Tim Montgomery & 9.78 & 10.22 & Black \\
2005 & Asafa Powell & 9.77 & 10.24 & Black \\
2006 & Justin Gatlin & 9.77 & 10.24 & Black \\
2006 & Asafa Powell & 9.77 & 10.24 & Black \\
2006 & Asafa Powell & 9.77 & 10.24 & Black \\
2007 & Asafa Powell & 9.74 & 10.27 & Black \\
2008 & Usain Bolt & 9.69 & 10.32 & Black \\
2009 & Usain Bolt & 9.58 & 10.44 & Black \\
\hline & & & &
\end{tabular}

\section{SPEED AND BODY SIZE}

Broadly speaking, larger animals travel faster, undulate their bodies and limbs less frequently and can exert greater forces. It was shown that these features of 'animal locomotion' are valid over the broadest range of animal body sizes, species and environments [2] $\left(\mathrm{M}=10^{-6}-10^{4} \mathrm{~kg}\right.$; sea, land, air). They are part of a much larger volume of observations of how the body size determines the functioning of animals [7-10]. In the unifying theory of animal locomotion $[2,11]$, the speeds and frequencies of fliers, runners and swimmers were derived from the argument that animal locomotion is the evolving configuration of the flow of animal mass on earth, which is analogous to the flow of water mass in river basins. The evolution of both flow structures 
(river water, animal mass) was deduced from the constructal law: 'For a finite-size flow system to persist in time (to live) it must evolve such that it provides easier and easier access to its currents' [12].

The animal was modeled as a body with a single length scale, $\mathrm{L}_{\mathrm{b}}$, such that $\mathrm{M} \sim \mathrm{\rho L}_{\mathrm{b}}^{3}$ (see Fig. 2a). The total work requirement has two parts: the work needed to lift the moving body away from the earth (against gravity), $\mathrm{W}_{1}$, and the work needed to penetrate through the surrounding medium in the horizontal direction, $\mathrm{W}_{2}$. Both $\mathrm{W}_{1}$ and $\mathrm{W}_{2}$ depend on the horizontal speed of locomotion, $\mathrm{V}$. The sum $\left(\mathrm{W}_{1}+\mathrm{W}_{2}\right)$ is minimal when the vertical loss $\mathrm{W}_{1}$ is of the same order as the horizontal loss $\mathrm{W}_{2}$. From this balance emerge analytically all the known scaling laws of animal locomotion (speeds, forces and frequencies) in air, on land and in water. For example, the speed-mass relations predicted for swimming and flying are

$$
\begin{gathered}
\mathrm{V}_{\text {swim }} \sim \mathrm{g}^{1 / 2} \mathrm{M}^{1 / 6} \rho^{-1 / 6}, \\
\mathrm{~V}_{\text {fly }} \sim\left(\frac{\rho}{\rho_{\mathrm{a}}}\right)^{1 / 3} \mathrm{~g}^{1 / 2} \mathrm{M}^{1 / 6} \rho^{-1 / 6},
\end{gathered}
$$

where the additional factor $\left(\rho / \rho_{\mathrm{a}}\right)^{1 / 3}$ is approximately 10 , because the air density is of order $\rho_{\mathrm{a}} \sim 1 \mathrm{~kg} / \mathrm{m}^{3}$ and the body density is of order $\rho \sim 10^{3} \mathrm{~kg} / \mathrm{m}^{3}$. For running, the predicted speed $\mathrm{V}_{\text {run }}$ falls between eqns (1) and (2): the factor $\left(\rho / \rho_{\mathrm{a}}\right)^{1 / 3}$ is replaced by a factor of order 1 for running on mud, sand and snow, and a factor below 10 for running on flat and dry surfaces.

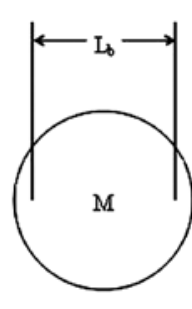

(a)

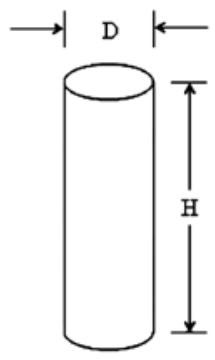

(b)
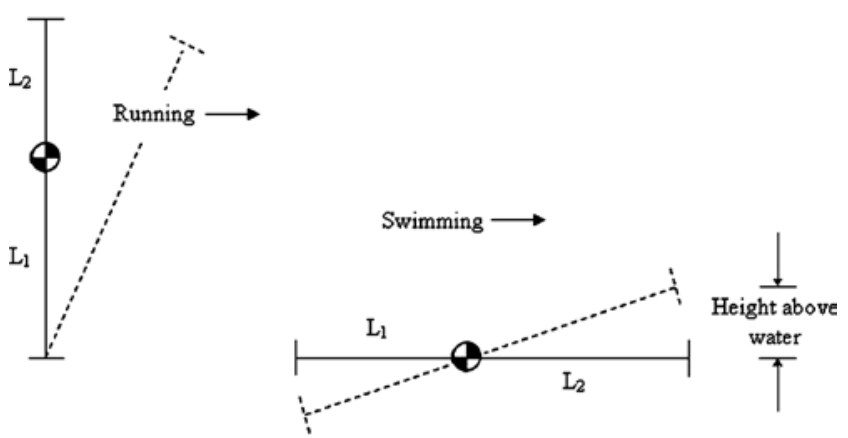

(c)

(d)

Figure 2: Models used to predict the scaling rules of animal locomotion: (a) one scale, (b) two scales. The length scales of falling-forward locomotion: (c) $\mathrm{L}_{1}$ for running, and (d) $\mathrm{L}_{2}$ for swimming. 
To predict the evolution of speed sports, in [1] we modeled the human body as a cylinder of height $\mathrm{H}$ and diameter D (Fig. 2b). We showed that the same scaling relations, eqns (1) and 2), can be derived more directly by regarding every case of animal movement as 'falling-forward locomotion', i.e. as a sequence of many cycles in which a body rises, falls forward and rights itself up again. The scale of the speed of falling vertically is the same as the scale of the speed of falling forward. In swimming, the vertical length scale of the saw-toothed trajectory of the body is D. The time scale of its free fall is the Galilean time $(\mathrm{D} / \mathrm{g})^{1 / 2}$, and the downward and forward speed scale is of order

$$
\mathrm{V}_{\text {swim }} \sim(\mathrm{gD})^{1 / 2} \text {. }
$$

This is also the horizontal speed of the water wave (of amplitude length scale D) generated by the swimming body. In running, the vertical length scale of the human body is $\mathrm{H}$, and the time scale of falling down and forward is $\mathrm{t} \sim(\mathrm{H} / \mathrm{g})^{1 / 2}$. The speed of falling forward is of order

$$
\mathrm{V}_{\text {run }} \sim(\mathrm{gH})^{1 / 2} \text {. }
$$

If the one-scale model $\left(\mathrm{D} \sim \mathrm{H} \sim \mathrm{L}_{\mathrm{b}}\right.$; Fig. $\left.2 \mathrm{a}\right)$ is used, then the single scale is $(D, H) \sim(M / \rho)^{1 / 3}$, and eqns (3) and (4) reproduce the original scaling relations, eqns (1) and (2).

\section{THE EFFECT OF ORIGIN}

To explain the phenomenon of Fig. 1, it is tempting to begin with the observation that blacks have body densities $(\rho)$ that are slightly (roughly 1 percent) larger than the body densities of whites [13-15]. This fact may be relevant to a comparison of the efforts needed by swimmers to stay afloat in place (treading water), but cannot explain the differences in horizontal speeds in running and swimming. Recall that the phenomenon of Fig. 1 is about swimming and running, not about swimming alone, or swimming in place.

Key is the observation that the body density does not appear in the formulas for the swimming and running speeds, eqns (3) and (4). The only physiological measure that matters is the height from which the mass falls - the water wave, eqn (3), and the human body, eqn (4).

Mass and height are key requirements for speed [1], but in a group of athletes with the same $\mathrm{M}$ and $\mathrm{H}$ there is another measurement that matters. During the falling-forward locomotion cycle of running, the body does not fall from the height $\mathrm{H}$ (the top of the head). What falls is the center of mass of the body, and it falls from the height $\mathrm{L}_{1}$ defined in Fig. 2c. Runners with a longer $\mathrm{L}_{1}$ should have the advantage.

For swimming, eqn (3) draws attention to the same aspect of the human body design. During the falling-forward motion of the water wave, the elevation above the water line (i.e. the amplitude of the water wave) is not the thickness of the body, D. The correct vertical length scale is proportional to the distance $\mathrm{L}_{2}$ measured from the center of mass to the top of the head (Fig. 2d). To the observer who travels horizontally with the same speed as the swimmer, the body of the swimmer is a lever (a seesaw) that oscillates about its center of mass and generates water waves. When the arm $\mathrm{L}_{2}$ is longer, the front part of the torso and the displaced water are lifted to and fall from a higher position, and they fall forward faster. The swimmer with a longer $\mathrm{L}_{2}$ (i.e. with a lower center of mass) should have the advantage.

Anthropometric measurements of large populations show that systematic differences exist among blacks, whites and Asians. The published evidence is massive: blacks have longer limbs than whites [16-18], and because blacks have longer legs and smaller circumferences (e.g. calves and arms), their center of mass is higher than that in other individuals of the same height [14, 17]. Asians and whites have longer torsos, therefore their centers of mass are lower. A large volume of measurements that 


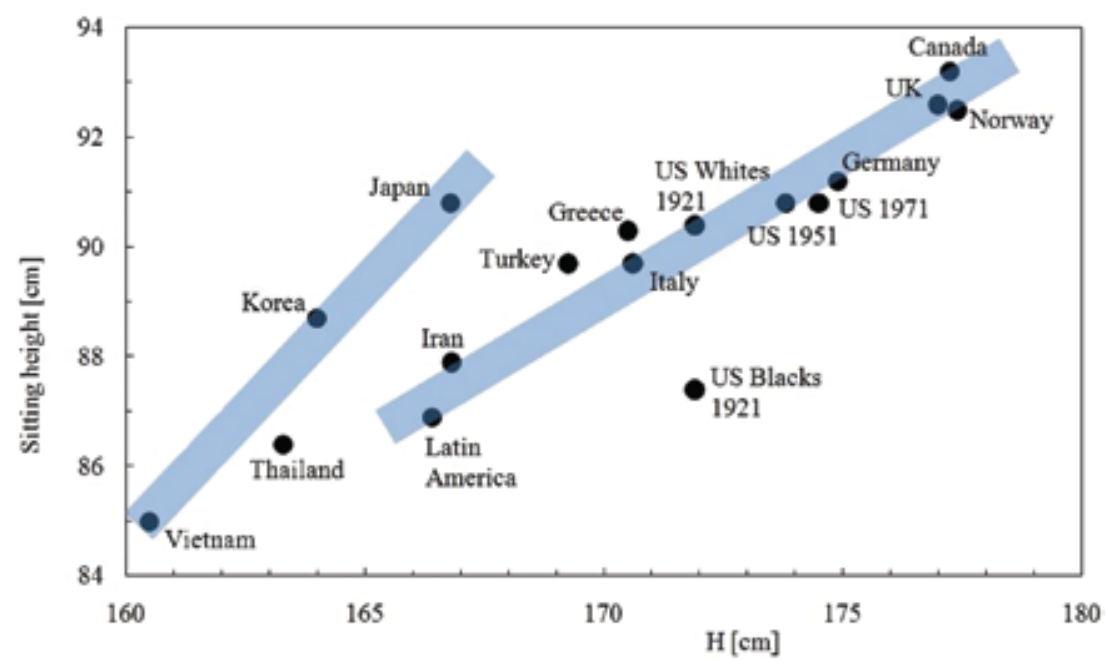

Figure 3: The heights and sitting heights of 17 groups of military men from selected populations (after Himes [19]): Vietnam [20]; Thailand [21]; Korea [22]; Latin America [23]; Iran [24]; Japan [25]; Turkey, Greece, Italy [26]; U.S. Whites 1921, U.S. Blacks 1921 [27]; U.S. Whites 1951 [28]; U.S. Whites 1971 [29]; Germany [30]; United Kingdom [31]; Canada [32]; Norway [33].

document these features is summarized in Fig. 3 and its caption. Measurements of 17 groups of military men from many parts of the globe were conducted in 14 independent studies and compiled by Himes [19] as the average stature (the height of the body, $\mathrm{H}$ ) versus the average height while seated. The sitting height is not exactly the $\mathrm{L}_{2}$ dimension defined in Fig. $2 \mathrm{c}$, but differences between sitting heights are indicative of how $\mathrm{L}_{2}$ varies from one group to the next.

Three conclusions follow from Fig. 3. First, Asians have the largest sitting heights among individuals with the same H. According to Fig. $2 d$ then, Asians should be most favored among swimmers who are not tall. This, by the way, agrees with the beginnings of speed records in swimming (Fig. 1, 1912-1920).

Second, whites also line up as a monotonic relation between sitting height (roughly $\mathrm{L}_{2}$ ) and total height $(\mathrm{H})$, but their $\mathrm{L}_{2}$ is lower than that for Asians. This correlation stretches from the shorter (Iran, Latin America) to the taller (Norway, UK, Canada).

Third, the measurements of the group of blacks fall well below those of the other groups. Their average sitting height $(87.5 \mathrm{~cm})$ is $3 \mathrm{~cm}$ shorter than the average sitting height of the group of men with the same average height $(172 \mathrm{~cm})$.

If the sitting height is an approximate measure of $\mathrm{L}_{2}$, then the dimension that dictates the speed in running $\left(\mathrm{L}_{1}\right)$ is 3.7 percent greater in blacks than in whites. At the same time, the dimension that governs speed in swimming is 3.5 percent greater in whites than in blacks.

These 3-percent differences in $\mathrm{L}_{1}$ (or $\mathrm{L}_{2}$ ) are consistent with other measurements. For example, according to [17] the upper- and lower-extremity bone lengths are significantly longer in adult black females than in white females. For the lower-extremity bone lengths, the difference is between $80.3 \pm$ $10.4 \mathrm{~cm}$ (black females) and $78.1 \pm 6.2 \mathrm{~cm}$ (white females). This difference of $2.2 \mathrm{~cm}$ represents 2.7 percent of the lower-extremity length, and it is of the same order as the 3.7 percent difference between the sitting heights of whites and blacks. 


\section{CONCLUSION}

In summary, 3 percent is the order of magnitude that differentiates between the positions of the centers of mass in the bodies of blacks and whites, and favors the two groups differently in the two speed sports: blacks in running, and whites in swimming.

For runners, the 3 percent increase in the correct height $\left[\mathrm{L}_{1}\right.$ instead of $\mathrm{H}$ in eqn (4)] means a 1.5 percent increase in the winning speed for the $100 \mathrm{~m}$ dash. This represents a 1.5 percent decrease in the winning time, for example, a drop from 10 to $9.85 \mathrm{~s}$. This change is enormous in comparison with the incremental decreases that differentiate between world records from year to year. In fact, the $0.15 \mathrm{~s}$ decrease corresponds to the evolution of the speed records over 20 years, from 1960 (Armin Hary) to 1991 (Carl Lewis). The 3 percent difference in $\mathrm{L}_{1}$ between groups represents an enormous advantage for black athletes.

For swimming, the conclusion is quantitatively the same, but in favor of white athletes. The 3 percent increase in the correct length $\left[\mathrm{L}_{2}\right.$, instead of $\mathrm{D}$ in eqn (3)] means a 1.5 percent increase in winning speed, and a 1.5 percent decrease in winning time. Because the winning times for 100 $\mathrm{m}$ freestyle are of the order of $50 \mathrm{~s}$, this represents a decrease of the order of $0.75 \mathrm{~s}$ in the winning time. This is a significant advantage for white swimmers, because it corresponds to evolution of the records over 10 years, for example, from 1976 (James Montgomery) to 1985 (Matt Biondi).

Further support for this explanation of the speed records phenomenon is provided by Fig. 4, which shows the evolution of the speed records set by women in the $100 \mathrm{~m}$ dash and the $100 \mathrm{~m}$ freestyle. Figure 4 for women is the same as Fig. 1 for men. The female sprinters that set the records tend to be black. This trend is a bit more recent than for men, but it is as evident. In swimming, the dominance of white women is evident throughout the modern era, just as it is for men.

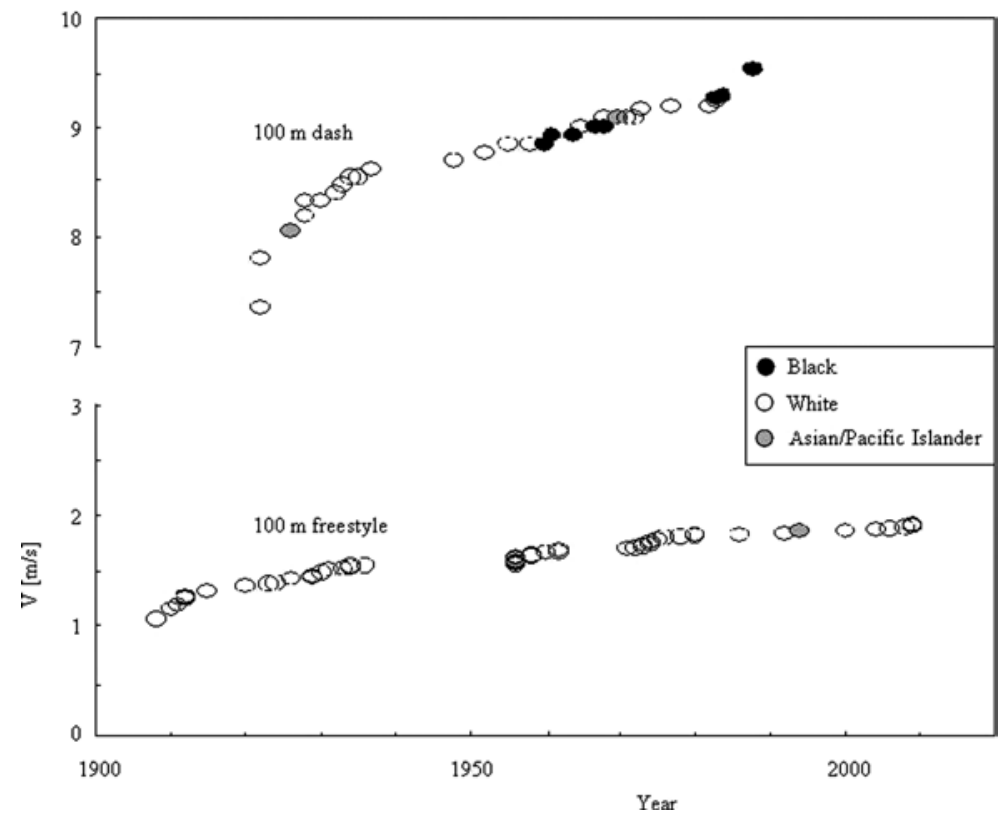

Figure 4: The evolution of women's world record speeds in running (100 m dash) and swimming (100 $\mathrm{m}$ freestyle). The data are from Tables 3 and 4. 
Table 3: Women's $100 \mathrm{~m}$ freestyle world records.

\begin{tabular}{|c|c|c|c|c|}
\hline Year & Name & Time (s) & Velocity $(\mathrm{m} / \mathrm{s})$ & Race \\
\hline 1908 & Martha Gerstung & 95.0 & 1.05 & White \\
\hline 1910 & C. Guttenstein & 86.6 & 1.15 & White \\
\hline 1911 & Daisy Curwen & 84.6 & 1.18 & White \\
\hline 1912 & Daisy Curwen & 80.6 & 1.24 & White \\
\hline 1912 & Fanny Durack & 79.8 & 1.25 & White \\
\hline 1912 & Fanny Durack & 78.8 & 1.27 & White \\
\hline 1915 & Fanny Durack & 76.2 & 1.31 & White \\
\hline 1920 & Ethelda Bleibtrey & 73.6 & 1.36 & White \\
\hline 1923 & Gertrude Ederle & 72.8 & 1.37 & White \\
\hline 1924 & Mariechen Wehselau & 72.2 & 1.39 & White \\
\hline 1926 & Ethil Lackie & 70.0 & 1.43 & White \\
\hline 1929 & Eleanor Ganatti & 69.8 & 1.43 & White \\
\hline 1929 & Albina Osinowich & 69.4 & 1.44 & White \\
\hline 1930 & Helene Madison & 68.0 & 1.47 & White \\
\hline 1931 & Helene Madison & 66.6 & 1.50 & White \\
\hline 1933 & Willy den Ouden & 66.0 & 1.52 & White \\
\hline 1934 & Willy den Ouden & 65.4 & 1.53 & White \\
\hline 1934 & Willy den Ouden & 64.8 & 1.54 & White \\
\hline 1936 & Willy den Ouden & 64.6 & 1.55 & White \\
\hline 1956 & Dawn Fraser & 64.5 & 1.55 & White \\
\hline 1956 & Cocky Gastelaars & 64.2 & 1.56 & White \\
\hline 1956 & Cocky Gastelaars & 64.0 & 1.56 & White \\
\hline 1956 & Dawn Fraser & 63.3 & 1.58 & White \\
\hline 1956 & Lorraine Crapp & 63.2 & 1.58 & White \\
\hline 1956 & Lorraine Crapp & 62.4 & 1.60 & White \\
\hline 1956 & Dawn Fraser & 62.0 & 1.61 & White \\
\hline 1958 & Dawn Fraser & 61.5 & 1.63 & White \\
\hline 1958 & Dawn Fraser & 61.4 & 1.63 & White \\
\hline 1958 & Dawn Fraser & 61.2 & 1.63 & White \\
\hline 1960 & Dawn Fraser & 60.2 & 1.66 & White \\
\hline 1962 & Dawn Fraser & 60.0 & 1.67 & White \\
\hline 1962 & Dawn Fraser & 59.9 & 1.67 & White \\
\hline 1962 & Dawn Fraser & 59.5 & 1.68 & White \\
\hline 1971 & Shane Gould & 58.9 & 1.70 & White \\
\hline 1972 & Shane Gould & 58.5 & 1.71 & White \\
\hline 1973 & Kornelia Ender & 58.25 & 1.72 & White \\
\hline 1973 & Kornelia Ender & 58.12 & 1.72 & White \\
\hline 1973 & Kornelia Ender & 57.61 & 1.74 & White \\
\hline 1973 & Kornelia Ender & 57.54 & 1.74 & White \\
\hline 1974 & Kornelia Ender & 57.51 & 1.74 & White \\
\hline 1974 & Kornelia Ender & 56.96 & 1.76 & White \\
\hline 1975 & Kornelia Ender & 56.38 & 1.77 & White \\
\hline 1975 & Kornelia Ender & 56.22 & 1.78 & White \\
\hline
\end{tabular}


Table 3: Continued

\begin{tabular}{llccl}
\hline Year & \multicolumn{1}{c}{ Name } & Time $(\mathrm{s})$ & Velocity $(\mathrm{m} / \mathrm{s})$ & Race \\
\hline 1976 & Kornelia Ender & 55.73 & 1.79 & White \\
1976 & Kornelia Ender & 55.65 & 1.80 & White \\
1978 & Barbara Krause & 55.41 & 1.80 & White \\
1980 & Barbara Krause & 54.98 & 1.82 & White \\
1980 & Barbara Krause & 54.79 & 1.83 & White \\
1986 & Kristin Otto & 54.73 & 1.83 & White \\
1992 & Jenny Thompson & 54.48 & 1.84 & White \\
1994 & Jingyi Le & 54.01 & 1.85 & Asian/Pacific Islander \\
2000 & Inge de Bruijn & 53.80 & 1.86 & White \\
2000 & Inge de Bruijn & 53.77 & 1.86 & White \\
2004 & Lisbeth Lenton & 53.66 & 1.86 & White \\
2004 & Jodie Henry & 53.52 & 1.87 & White \\
2006 & Lisbeth Lenton & 53.42 & 1.87 & White \\
2006 & Britta Steffen & 53.30 & 1.88 & White \\
2008 & Lisbeth Trickett & 52.88 & 1.89 & White \\
2009 & Britta Steffen & 52.85 & 1.89 & White \\
2009 & Britta Steffen & 52.56 & 1.90 & White \\
2009 & Britta Steffen & 52.22 & 1.91 & White \\
2009 & Britta Steffen & 52.07 & 1.92 & White \\
\hline
\end{tabular}

Table 4: Women's $100 \mathrm{~m}$ dash world records.

\begin{tabular}{llccl}
\hline Year & \multicolumn{1}{c}{ Name } & Time $(\mathrm{s})$ & Velocity $(\mathrm{m} / \mathrm{s})$ & \multicolumn{1}{c}{ Race } \\
\hline 1922 & Marie Mejzlikova & 13.6 & 7.35 & White \\
1922 & Mary Lines & 12.8 & 7.81 & White \\
1926 & Gundel Whittmann & 12.4 & 8.06 & White \\
1928 & Kinue Hitomi & 12.2 & 8.20 & Asian/Pacific Islander \\
1928 & Myrtle Cook & 12.0 & 8.33 & White \\
1930 & Tollien Schuurman & 12.0 & 8.33 & White \\
1932 & Tollien Schuurman & 11.9 & 8.40 & White \\
1932 & Stanislawa Walasiewicz & 11.9 & 8.40 & White \\
1933 & Stanislawa Walasiewicz & 11.8 & 8.47 & White \\
1934 & Stanislawa Walasiewicz & 11.7 & 8.55 & White \\
1935 & Helen Stephens & 11.7 & 8.55 & White \\
1937 & Stanislawa Walasiewicz & 11.6 & 8.62 & White \\
1948 & Fanny Blankers-Koen & 11.5 & 8.70 & White \\
1952 & Marjorie Jackson & 11.4 & 8.77 & White \\
1955 & Shirley Strickland & 11.3 & 8.85 & White \\
1958 & Vera Krepkina & 11.3 & 8.85 & White \\
1960 & Wilma Rudolph & 11.3 & 8.85 & Black \\
1961 & Wilma Rudolph & 11.2 & 8.93 & Black \\
\hline
\end{tabular}


Table 4: Continued

\begin{tabular}{llccl}
\hline Year & \multicolumn{1}{c}{ Name } & Time $(\mathrm{s})$ & Velocity $(\mathrm{m} / \mathrm{s})$ & \multicolumn{1}{c}{ Race } \\
\hline 1964 & Wyomia Tyus & 11.2 & 8.93 & Black \\
1965 & Irena Kirszenstein & 11.1 & 9.01 & White \\
1967 & Barbara Ferrell & 11.1 & 9.01 & Black \\
1968 & Lyudmila Samotyosova & 11.1 & 9.01 & White \\
1968 & Irena Szewinska & 11.1 & 9.01 & White \\
1968 & Wyomia Tyus & 11.0 & 9.09 & Black \\
1970 & Chi Cheng & 11.0 & 9.09 & Asian/Pacific Islander \\
1970 & Renate Meißner* & 11.0 & 9.09 & White \\
1971 & Renate Meißner* & 11.0 & 9.09 & White \\
1972 & Renate Meißner* & 11.0 & 9.09 & White \\
1972 & Ellen Strophal* & 11.0 & 9.09 & White \\
1972 & Eva Gleskova & 11.0 & 9.09 & White \\
1973 & Renate Meißner* & 10.9 & 9.17 & White \\
1973 & Renate Meißner* & 10.9 & 9.17 & White \\
1977 & Marlies Oelsner* & 10.88 & 9.19 & White \\
1982 & Marlies Gohr* & 10.88 & 9.19 & White \\
1983 & Marlies Gohr* & 10.81 & 9.25 & White \\
1983 & Evelyn Ashford & 10.79 & 9.27 & Black \\
1984 & Evelyn Ashford & 10.76 & 9.29 & Black \\
1988 & Florence Griffith-Joyner & 10.49 & 9.53 & Black \\
\hline
\end{tabular}

*East German athlete (steroid usage suspected).

Even more support for the theoretical explanation advanced here is the relative absence of Asian record holders, especially during the past two decades. According to the physics of fallingforward locomotion (Figs 2c and d), Asians should have an advantage in swimming, but not in running, because their torsos are relatively longer (cf. Fig. 3, if the height $\mathrm{H}$ is fixed). This is in accord with the evolution of records for men (Fig. 1) and women (Fig. 4). Asians would be favored among swimmers with the same height. However, the quest for speed has driven the sport toward longer torsos $\left(\mathrm{L}_{2}\right)$, not longer relative torsos $\left(\mathrm{L}_{2} / \mathrm{H}\right)$. This is why the current trend in swimming is toward tall individuals (large $\mathrm{H}$ ), and in this direction Asians are at a disadvantage relative to athletes of European origin. Still, because female swimmers are not (yet) as tall as male swimmers, Asians continue to be competitive in the $100 \mathrm{~m}$ freestyle for women. This opportunity will end (as it did in men's swimming), because the winners' podium is being taken over (predictably, cf. [1]) by taller and taller athletes.

One of the reviewers suggested that our discovery in this paper and in Ref. [1] has much broader implications in the evolution of speed in sports. The reviewer questioned the evolution of size and shape in dog racing. We believe that the answer is the same as in this paper and Ref. [1]: the evolution of dog racing should be toward dogs that are taller, with longer legs and higher centers of mass off the ground. The same prediction holds for the evolution of winning horses in horse racing. Furthermore, bicycle racing and boat racing (crew) should follow the same trend-the winners should tend to be taller athletes riding on taller bicycles, and athletes that sit taller in longer boats. 


\section{ACKNOWLEDGEMENT}

Adrian Bejan's research was supported by the National Science Foundation.

\section{REFERENCES}

[1] Charles, J.D. \& Bejan, A., The evolution of speed, size and shape in modern athletics. J. Exp. Biol., 212, pp. 2419-2425, 2009. doi:10.1242/jeb.031161

[2] Bejan, A. \& Marden, J.H., Unifying constructal theory for scale effects in running, swimming and flying. J. Exp. Biol., 209, pp. 238-248, 2006. doi:10.1242/jeb.01974

[3] Cooper, R.S. \& David, R., The biological concept of race and its application to public health and epidemiology. Journal of Health Politics, Policy and Law, 11, pp. 97-116, 1986. doi:10.1215/03616878-11-1-97

[4] AAPA, Statement on biological aspects of race. American Journal of Physical Anthropology, 101, pp. 569-570, 1996. doi:10.1002/ajpa.1331010408

[5] Caprio, S., Daniels, S.R., Drewnowski, A., Kaufman, F.R., Palinkas, L.A., Rosenbloom, A.L. \& Schwimmer, J.B., Influence of race, ethnicity, and culture on childhood obesity: implications for prevention and treatment. Obesity, 16(12), pp. 2566-2577, 2008. doi:10.1038/oby.2008.398

[6] Bell, A.V., Richerson, P.J. \& McElreath, R., Culture rather than genes provide greater scope for the evolution of large-scale human prosociality. PNAS, 106(42), pp. 17671-17674, 2009. doi:10.1073/pnas.0903232106

[7] Schmidt-Nielsen, K., Scaling: Why is Animal Size so Important? Cambridge University Press: Cambridge, UK, 1984.

[8] Weibel, E.R., Symmorphosis: on Form and Function in Shaping Life. Harvard University Press: Cambridge, MA, 2000.

[9] Ahlborn, B.K., Zoological Physics, Springer: Berlin, 2004.

[10] Hoppeler, H. \& Weibel, E.R., Scaling functions to body size: theories and facts, special issue. J. Exp. Biol., 208, pp. 1573-1769, 2005. doi:10.1242/jeb.01630

[11] Bejan, A., Shape and Structure, from Engineering to Nature, Cambridge University Press: Cambridge, 2000.

[12] Bejan, A., Advanced Engineering Thermodynamics, 2nd edn, Wiley: New York, 1997.

[13] Schutte, J.E., Townsend, E.J., Hugg, J., Shoup, R.F., Malina, R.M. \& Blomqvist, G., Density of lean body mass is greater in Blacks than in Whites. J. Appl. Physiol.: Respirat. Environ. Exercise Physiol., 56, pp. 1647-1649, 1984.

[14] Wagner, D.R. \& Heyward, V.H., Measures of body composition in blacks and whites: a comparative review. Am. J. Clin. Nutr., 71, pp. 392-402, 2007.

[15] Deurenberg, P., Yap, M. \& van Staveren, W., A. Body mass index and percent body fat: a meta analysis among different ethnic groups. Int. J. Obes, 22, pp. 1164-1171, 1998. doi:10.1038/sj.ijo.0800741

[16] Slaughter, M.H., Lohman, T.G., Boileau, R.A., Horswill, C.A., Stillman, R.J., van Loan, M.D. \& Bemben, D., A. Skinfold equations for estimation of body fatness in children and youth. Human Biol., 60, pp. 709-723, 1988.

[17] Ortiz, O., Russell, M., Daley, T.L., Baumgartner, R.N., Waki, M., Lichtman, S., Wang, J., Pierson, Jr. R.N. \& Heymsfield, S.B., Differences in skeletal muscle and bone mineral mass between black and white females and their relevance to estimates of body composition. Am. J. Clin. Nutr., 55, pp. 8-13, 1992.

[18] Fernandez, J.R., Heo, M., Heymsfield, S.B., Pierson, Jr. R.N., Pi-Sunyer, F.X., Wang, Z.M., Wang, J., Hayes, M., Allison, D.B. \& Gallagher, D., Is percentage body fat differentially related to body mass index in Hispanic Americans, African Americans, and European Americans? Am. J. Clin. Nutr., 77, pp. 71-75, 2003. 
[19] Himes, J.H., Racial variation in physique and body composition. Can. J. Spt. Sci., 13(2), pp. 117-126, 1988.

[20] White, R.M., Anthropometric Survey of the Armed Forces of the Republic of Vietnam, US Army Natick Laboratories: Natick, MA, 1964.

[21] White, R.M., Anthropometric Survey of the Royal Thai Armed Forces, US Army Natick Laboratories: Natick, MA, 1964.

[22] Kennedy, J.C. \& Rowland, G.W., Analysis of the Impact of Body Size upon Korean Soldier Performance with US Weapons and Equipment, Report R\&C-70-7-104, Rowland and Company: Haddonfield, New Jersey, 1970.

[23] Dobbins, D.A. \& Kindick, C.M., Anthropometry and the Latin-American Armed Forces, Research Report No. 10 (Interim Report), US Army Tropic Test Center, Fort Clayton, Canal Zone, 1967.

[24] Noorani, S. \& Dillard, Jr. C.N., Anthropometric Survey of the Imperial Iranian Armed Forces, Technical Report of the Combat Research and Evaluation Center. Imperial Iranian Ground Forces: Teheran, Iran, 1970.

[25] Oshima, M., Fujimoto, T., Ogneo, T., Tokbinmatsu, N., Mori, T., Tanaka, I., Watanaabe, T. \& Alexander, M., Anthropometry of Japanese Pilots, Reports of the Aero Medical Laboratory (Tokyo, Japan), vol. 2, pp. 70-114, 1962.

[26] Hertzberg, H.T.E., Churchill, E. Dupertuis, C.W., White, R.M. \& Damon, A., Anthropometric Survey of Turkey, Greece and Italy, Macmillan Company: New York, 1963.

[27] Davenport, C.B. \& Love, A.G., Army anthropology. In: Medical Department of the United States Army in the World War, vol. 15, part 2. Office of the Surgeon General, Department of the Army: Washington, 1921.

[28] Newman, R.W. \& White, R.M., Reference Anthropometry of Army Men, Report no 180. Environmental Protection Branch, U.S. Army Quartermaster Climatic Research Laboratory: Lawrence, MA, 1951.

[29] Churchill, E., McConville, J.T., Laubach, L.L. \& White, R.M., Anthropometry of US Army Aviators-1970, Technical report 72-52-CE, US Army Natick Laboratories: Natick, MA, 1971.

[30] Goltz, E. \& Platz, B., Anthropometriche Studien, Report T-418, Der Deutschen Entwicklungsgesellschaft: Augsburg, Germany, 1965.

[31] Simpson, R.E. \& Bolton, C.B., An Anthropometric Survey of 200 RAF and RN Aircrew and the Application of the Data to Garment Size Rolls, Technical Report 67125, Royal Aircraft Establishment: Farnborough, Hans, 1968.

[32] Samuel, G.D. \& Smith, E.M.B., A Comparison of Seven Anthropometric Variables of American, British, and Canadian Pilots, Report no 322, Royal Air Force Institute of Aviation Medicine: Farnborough, Hants, 1965.

[33] Udjus, L.G., Anthropometrical Changes in Norwegian Men in the Twentieth Century, Norwegian Monographs on Medical Science, Universitetsforlaget: Oslo, Norway, 1964. 